\title{
Case Report: Combination Therapy with Liposomal Amphotericin B, N-Methyl Meglumine Antimoniate, and Pentamidine Isethionate for Disseminated Visceral Leishmaniasis in a Splenectomized Adult Patient
}

\author{
Hareton Teixeira Vechi, ${ }^{1}$ Ana Solange Vasconcelos de Sousa, ${ }^{2}$ Mirella Alves da Cunha, ${ }^{1}$ Jeffrey Jon Shaw, ${ }^{3}$ \\ and Kleber Giovanni Luz ${ }^{1 \star}$ \\ ${ }^{1}$ Department of Infectious Diseases, Hospital Giselda Trigueiro, Universidade Federal do Rio Grande do Norte, Natal, Rio Grande do Norte, Brazil; \\ ${ }^{2}$ Hospital Giselda Trigueiro, Natal, Rio Grande do Norte, Brazil; ${ }^{3}$ Department of Parasitology, Instituto de Ciências Biomédicas,
} São Paulo University, São Paulo, São Paulo, Brazil

\begin{abstract}
In immunocompromised patients, visceral leishmaniasis (VL) can present with atypical clinical symptoms that include poor response to treatment. No optimal therapeutic regimen is available for such cases. In a splenectomized male patient, we observed a disseminated form of the disease in the liver, bone marrow, lymph nodes, and gastrointestinal tract. There was an apparent clinical improvement when he was initially treated with liposomal amphotericin $B(L-A m B)$, but this was followed by a relapse involving severe clinical symptoms. He was finally treated successfully with a combination of $L-A m B$, meglumine antimoniate, and pentamidine isethionate. It is important to include asplenia as an immunosuppressive condition that induces exotic VL pathologies. In such cases, combination anti-Leishmania drug therapy should be considered.
\end{abstract}

\section{INTRODUCTION}

Visceral leishmaniasis (VL) is a clinical condition caused by the protozoan parasites Leishmania (Leishmania) donovani and Leishmania (Leishmania) infantum. ${ }^{1}$ Current estimates indicate that approximately 200,000 to 400,000 cases of VL occur globally every year with mortality rates of up $10 \%,{ }^{2}$ but it is estimated that there are many more subclinical cases. More than $90 \%$ of the VL cases in Latin America occur in Brazil and are caused by $L$. (L.) infantum. ${ }^{1,3}$ Classically, VL presents clinically prolonged fever, hepatosplenomegaly, and pancytopenia. ${ }^{1,4}$

The increasing incidence of immunosuppressive conditions, especially HIV/AIDS infection, has led to changes in the epidemiology, clinical symptoms, evolution, and treatment of VL. Among immunocompromised patients, the infection can involve other organs besides the traditional reticuloendothelial system, such as the gastrointestinal tract. ${ }^{4,5}$ In immunosuppressed patients, treatment failure is greater and is associated with more relapse episodes. So far, no optimal therapeutic regimen has been defined for the latter situations principally because of a lack of sufficient data to formulate such recommendations. ${ }^{4,5}$

Here, we describe a case of disseminated VL in a splenectomized adult patient who initially failed to respond to liposomal amphotericin $\mathrm{B}(\mathrm{L}-\mathrm{AmB})$ monotherapy and, then, was successfully treated with a combination therapy of $L-A m B$, $\mathrm{N}$-methyl meglumine antimoniate (meglumine antimoniate; $\mathrm{MA})$ and pentamidine isethionate.

\section{CASE REPORT}

A 46-year-old black man was referred to our emergency department because of a period of continued fever of 1 year and 5 months. He reported an indolent onset of a high fever (axillary temperature of $39^{\circ} \mathrm{C}$ ), with two daily peaks, preceded by chills, asthenia, anorexia, and profuse sweating. This was

\footnotetext{
*Address correspondence to Kleber Giovanni Luz, Department of Infectious Diseases, Hospital Giselda Trigueiro, Universidade Federal do Rio Grande do Norte, 110 Cônego Monte St., Natal 59037-170, Brazil. E-mail: klebergluz@gmail.com
}

accompanied by loss of $21 \mathrm{~kg}$ in his body weight. In addition, he had had five episodes per day of diarrhea for about 12 months without blood, pus, and mucus that were associated with a sharp abdominal pain in the right hypochondrium and flank. Four months ago, the patient noticed the appearance of lymphadenopathy in axillary, cervical, and inguinal chains with progressive increase in size. He also reported occasional episodes of bilateral small-volume epistaxis with bright red color unrelated to local trauma. His medical history is remarkable for a splenectomy that was performed 20 years ago because of an abdominal gunshot wound. The patient has a history of alcohol consumption and smoked two packs of cigarettes a day. He was single and engaged in unprotected heterosexual relations. He was born and lives in Ceará-Mirim city, an endemic VL region of Rio Grande do Norte state, Brazil.

On admission, the vital signs were normal. He was lucid and oriented. His physical examination was remarkable for pallor and cachexia (body weight of $50 \mathrm{~kg}$ and body mass index of $16.9 \mathrm{~kg} / \mathrm{m}^{2}$ ). The abdominal examination showed a median xiphobic scar and enlargement of liver to $26 \mathrm{~cm}$ with a firm consistency and smooth surface. He had enlarged lymph nodes that were mobile, non-tender, and with soft consistency in inguinal, axillary, and anterior and posterior cervical chains. The patient also exhibited parotid swelling and digital clubbing. Initial laboratory tests showed a moderate anemia, discrete elevation of aminotransferases enzymes, a low albumin/ globulin ratio and prolonged prothrombin time (Table 1). The serologic tests were negative for HIV, hepatitis $B$ and $C$, and syphilis. The computed tomography of chest was normal. Blood cultures were negative for bacteria and fungi. Stool ova and parasite test in series of six samples was positive for Entamoeba histolytica/dispar cysts.

An abdominal-pelvic magnetic resonance showed enlargement of the liver extending to the right iliac fossa with blunt and slightly lobulated edges and mildly diffused heterogeneous sign of hepatic parenchyma. The presence of enlarged lymph nodes was noted in the periportal, peripancreatic, and inguinal chains. One possible diagnosis was a form of cancer, so a biopsy was performed on the patient's left inguinal lymph node. The histopathological study revealed 
TABLE 1

Clinical findings and laboratory test results throughout the patient's treatment and follow-up

\begin{tabular}{|c|c|c|c|c|c|c|}
\hline & \multicolumn{2}{|c|}{ 1st hospitalization } & \multicolumn{2}{|c|}{ 2nd hospitalization } & \multirow[b]{2}{*}{$\begin{array}{l}\text { Twelve months after } \\
\text { combination therapy }\end{array}$} & \multirow[b]{2}{*}{ Reference range } \\
\hline & $\begin{array}{l}\text { Before } \\
\text { therapy }\end{array}$ & $\begin{array}{l}\text { After } \\
\text { therapy }\end{array}$ & $\begin{array}{l}\text { Before combination } \\
\text { therapy }\end{array}$ & $\begin{array}{l}\text { After combination } \\
\text { therapy }\end{array}$ & & \\
\hline Enlargement of liver & $\begin{array}{l}14 \mathrm{~cm} \text { from } \\
\mathrm{RCM}\end{array}$ & $\begin{array}{l}6 \mathrm{~cm} \text { from } \\
\mathrm{RCM}\end{array}$ & $4 \mathrm{~cm}$ from $\mathrm{RCM}$ & $3 \mathrm{~cm}$ from $\mathrm{RCM}$ & $0 \mathrm{~cm}$ from $\mathrm{RCM}$ & Until $2 \mathrm{~cm}$ from $\mathrm{RCM}$ \\
\hline Hemoglobin & 100 & 120 & 80 & 80 & 140 & $133-180 \mathrm{~g} / \mathrm{L}$ \\
\hline White blood cells & $5.0 \times 10^{9}$ & $7.5 \times 10^{9}$ & $7.0 \times 10^{9}$ & $15 \times 10^{9}$ & $13.1 \times 10^{9}$ & $4.5-10.0 \times 10^{9}$ \\
\hline Neutrophills & $37 \%$ & $52 \%$ & $53 \%$ & $47 \%$ & $58 \%$ & $58-66 \%$ \\
\hline Lymphocytes & $59 \%$ & $31 \%$ & $42 \%$ & $24 \%$ & $38 \%$ & $20-46 \%$ \\
\hline Platelets & $345 \times 10^{9}$ & $441 \times 10^{9}$ & $526 \times 10^{9}$ & $360 \times 10^{9}$ & $397 \times 10^{9}$ & $150-450 \times 10^{9}$ \\
\hline Serum creatinine & 58.3 & 53.0 & 79.6 & 97.2 & 88.4 & $50-110 \mu \mathrm{mol} / \mathrm{L}$ \\
\hline Serum urea & 2.7 & 4.3 & 7.2 & 5.5 & 7.7 & $2.9-8.2 \mathrm{mmol} / \mathrm{L}$ \\
\hline Sodium & 137 & 133 & 129 & 140 & 136 & $135-145 \mathrm{mEg} / \mathrm{L}$ \\
\hline Potassium & 4.5 & 4.2 & 3.9 & 3.4 & 3.9 & $3.5-5.1 \mathrm{mEq} / \mathrm{L}$ \\
\hline Amylase & ND & ND & 130 & 180 & 54 & $0-220 \mathrm{IU} / \mathrm{L}$ \\
\hline Glucose (fasting) & 4.6 & 4.8 & 3.9 & 4.2 & 4.1 & $3.9-6.1 \mathrm{mmol} / \mathrm{L}$ \\
\hline Aspartate aminotransferase & 29 & 55 & 89 & 51 & 40 & $0-37$ IU/L \\
\hline Alanine aminotransferase & 47 & 29 & 56 & 20 & 56 & $0-42$ IU/L \\
\hline Albumin & 24.7 & 36.9 & 21 & 26 & 53 & $38-51 \mathrm{~g} / \mathrm{L}$ \\
\hline Globulin & 89 & 78 & 82 & 86 & 30 & $25-33 \mathrm{~g} / \mathrm{L}$ \\
\hline Total bilirubin & 7.7 & ND & 3.9 & 7.5 & 14.8 & $3.4-17.1 \mu \mathrm{mol} / \mathrm{L}$ \\
\hline $\begin{array}{l}\text { Prothrombin time/International } \\
\text { normalized ratio }\end{array}$ & $18 / 1.35$ & $14.9 / 1.1$ & $16.9 / 1.2$ & $17.1 / 1.1$ & $15.2 / 1.1$ & $9.0-13.5$ seconds $/ 0.8-1.2$ \\
\hline Prothrombin activity & $52 \%$ & $80 \%$ & $60 \%$ & $80 \%$ & $82 \%$ & $\geq 70 \%$ \\
\hline
\end{tabular}

hyperplasia of lymphoid and histiocytic tissue with granulomatous organization exhibiting amastigote forms of Leishmania inside epithelioid histiocytes in Giemsa staining, characterizing a lymphadenitis due to a leishmanial infection. The lymph node architecture was preserved and no other underlying pathology, as lymphoma or other cancers, was detected (Figure 1). The patient subsequently underwent a bone marrow aspirate that revealed the presence of numerous extra- and intracellular amastigote. The Kalazar Detect ${ }^{\mathrm{TM}}$ Rapid Test (InBios International, Inc., Seattle, WA) for VL was positive.

From the results of the examinations, it was concluded that the patient was suffering from disseminated VL, and he was treated with L-AmB at $4 \mathrm{mg} / \mathrm{kg}$ daily for 5 days, following the recommendations of the Brazilian guidelines for management of VL. ${ }^{6} \mathrm{He}$ was also given a daily dose of $1.5 \mathrm{gm}$ of metronidazole for 7 days followed by a single dose of $1.5 \mathrm{gm}$ of Teclozine for intestinal amebiasis. After 4 days of treatment with amphotericin $\mathrm{B}$, the fever had disappeared, and the patient recovered his appetite. The diarrhea was completely resolved. There was reduction of his liver enlargement from $26 \mathrm{~cm}$ to $18 \mathrm{~cm}$ and lymphadenopathy decreased in size, but not completely. The laboratory tests showed improvement of hemoglobin level (Table 1). Parasitological reassessment, as a test of cure, was not needed because the patient showed a timely clinical response. Then, the patient was discharged from the hospital with recommendations of outpatient followup. After 2 months, the patient was readmitted to our service because of recurrence of diarrhea for 1 month, associated with weight loss of $6 \mathrm{~kg}$, without abdominal pain and fever. On physical examination, he had hepatomegaly of $16 \mathrm{~cm}$ and maintained enlarged lymph nodes in cervical, axillary, and inguinal chains. The laboratory tests revealed a worsening anemia and elevation of aminotransferases level (Table 1).

The patient underwent a colonoscopy, whose result was normal, but rectal biopsies were performed. The histopathology of rectal biopsy fragment showed a diffuse histiocytic infiltrate containing amastigote forms of Leishmania sp. in the Giemsa staining. Again, bone marrow aspirate was performed, revealing a few amastigote forms of Leishmania $\mathrm{sp}$. An axillary lymph node biopsy was also performed and the histopathology showed lymphadenitis with numerous

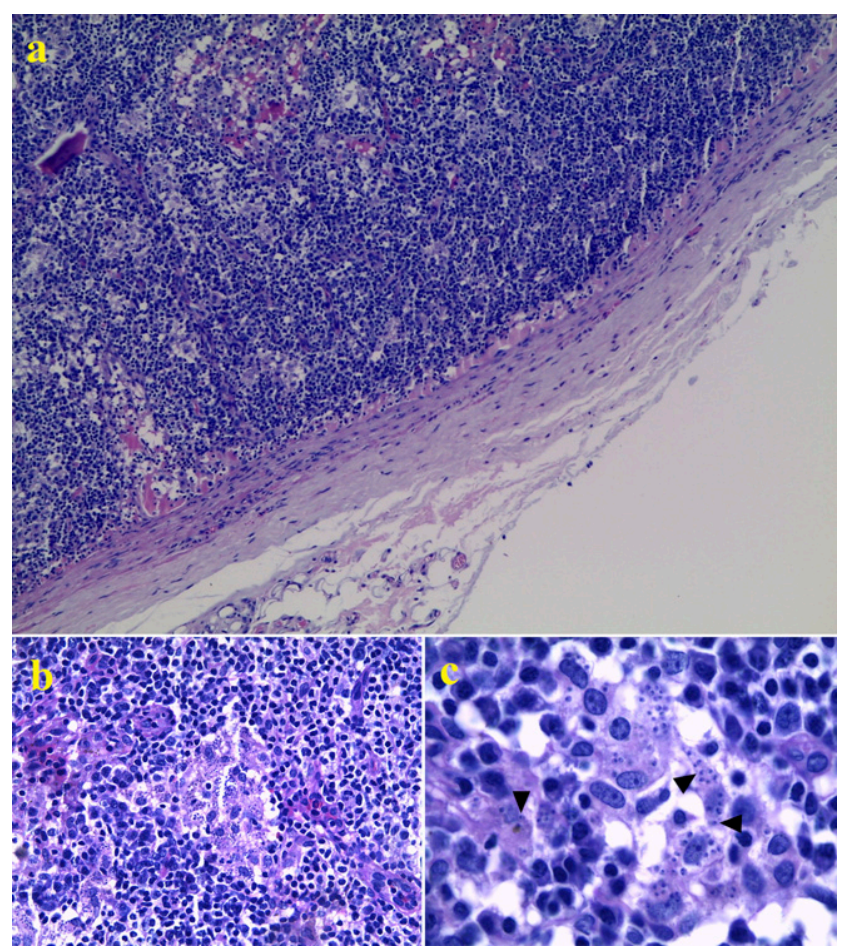

FIGURE 1. Photomicrography of the patient's inguinal lymph node biopsy. Hyperplasia of lymphoid and histiocytic tissue with granulomatous organization, visualized at $\times 100$ magnification (A), exhibiting amastigote forms of Leishmania (arrowhead) inside epithelioid histiocytes stained with Giemsa, visualized at $\times 400$ (B) and, especially, at $\times 1,000$ magnification (C). This figure appears in color at www.ajtmh.org. 
amastigotes inside macrophages in the Giemsa staining. This time, the patient was given a combination of L-AmB at $4 \mathrm{mg} / \mathrm{kg}$ daily intravenously for 10 days, MA at $10 \mathrm{mg} / \mathrm{kg} /$ day (expressed in $\mathrm{mg}$ of pentavalent antimony $\left[\mathrm{Sb}^{5+}\right] / \mathrm{kg}$ ) intravenously for 28 days, and pentamidine isethionate at $3 \mathrm{mg} / \mathrm{kg}$ twice a week intramuscularly for 4 weeks. The symptoms disappeared completely. The patient did not develop any toxicity related to the treatment. Twelve months after combination therapy, the patient remained asymptomatic, regained $19 \mathrm{~kg}$, and his physical examination showed no more visceromegalias neither lymphadenopathy. The laboratory tests performed 12 months after combination therapy are given in Table 1.

\section{DISCUSSION}

In the present case, the finding of Leishmania sp. amastigotes in lymph nodes, bone marrow aspirate, and rectal mucosa, together with clinical picture, led us to conclude the patient had a disseminated form of VL. The clinical VL symptoms seen in our patient are mainly associated with immunocompromised patients. ${ }^{7,8}$ Splenectomy has been known to have deleterious effects on humoral and cellular immunity. ${ }^{9}$ We, therefore, consider that asplenia should be included as a predisposing immunosuppressive condition for VL because this classification relates to both prognosis and treatment. ${ }^{5}$

Lymphadenopathy is an uncommon clinical presentation of $\mathrm{VL}$, except in Sudan where it is a prominent feature $(72 \%$ of cases) and disease is caused by $L$. donovani. ${ }^{1,5,10}$ The lymph node involvement is rare in $L$. infantum infections. ${ }^{11}$ Although the isolate of Leishmania sp. in the case has not been identified at the species level, most of VL cases in Brazil are caused by $L$. infantum ${ }^{1,3,5,6}$ and the patient has not traveled to endemic regions for $L$. donovani ${ }^{1,10}$ or Leishmania amazonensis, ${ }^{12}$ another agent that unusually causes VL with lymphadenopathy. From what we observed in the patient's histopathological studies, lymph nodes enlargement can be explained by hypertrophy and hyperplasia of macrophages and lymphocytes.

One of the symptoms initially reported by the patient were daily bouts of diarrhea associated with abdominal pains. He was treated for amebiasis as $E$. histolytica/dispar cysts were found in fecal samples. The bouts of diarrhea ceased but when his VL symptoms returned, so did bouts of diarrhea, which were associated with loss of weight, but they were not painful and there was no evidence of intestinal parasite infections. Moreover, chronic colitis caused by $L$. infantum was previously reported in both animals and humans. ${ }^{13,14}$ Our finding of amastigotes in the rectal biopsy raises the possibility of more extensive leishmanial lesions in the intestine. Digestive disturbances caused by such lesions could be related to nutritional problems that result in loss of weight. During treatment of the relapse, the bouts of diarrhea receded and the patient began to gain weight.

We believe that this clinical presentation of VL was due to splenectomy performed 20 years ago. The spleen is one of the largest and most important organs of reticuloendothelial system and becomes the main reservoir of Leishmania in VL, ${ }^{15}$ and in refractory cases, splenectomy may be performed to promote debulking of parasitic load. ${ }^{16}$ Furthermore, VL has an incubation period ranging from 10 days to 24 months, with an average of 2-6 months. ${ }^{1}$ Therefore, the patient acquired Leishmania infection after the splenectomy and, in the absence of the spleen, the parasitic burden was distributed widely to other organs of reticuloendothelial system, as lymph nodes and gastrointestinal tract.

The main differential diagnosis for VL in this patient was with malignancy. We were concerned about the possibility of lymphoma, especially a low-grade non-Hodgkin lymphoma. The patient had an indolent clinical condition characterized by fever, lymphadenopathy, and visceromegaly for 1 year and 5 months. That is why the patient initially underwent an inguinal lymph node biopsy. However, malignancy was ruled out because the lymph node architecture was preserved in the histopathological study. On the other hand, VL can be synchronously associated with solid tumors, including lymphoma, or can result in an extreme immune dysregulation leading to lymphoproliferative disorders. ${ }^{17,18}$ Considering the recurrence of symptoms and still-enlarged lymph nodes, the patient underwent another lymph node biopsy and the hypothesis of malignancy was discarded once again.

The patient exhibited anemia, but not pancytopenia, a classical laboratory finding of VL cases. ${ }^{5,19}$ The pathogenesis of hematological abnormalities is complex and multifactorial. ${ }^{20}$ Cytopenias have not been prominent in patients with VL who have undergone splenectomy. ${ }^{21}$ The patient's history of previous splenectomy makes us infer that the hypersplenism is one of the most important mechanisms contributing to pancytopenia in VL, especially for white blood cells and platelets. On the other hand, when compared with splenectomized persons' complete blood count for nonhematological indications, ${ }^{22}$ the patient had relatively lower blood cell counts at baseline that, after the combination treatment, normalized. The first bone marrow aspirate showing a high parasitic load suggests the role of direct bone marrow invasion by Leishmania in causing these "relative cytopenias" in our patient.

Visceral leishmaniasis usually lasts about 6 months, ${ }^{23}$ after which, without specific treatment, death ensues because of bacterial superinfections and/or hemorrhage. These complications are associated with severe leukopenia and thrombocytopenia, respectively. ${ }^{24}$ We believe the splenectomy contributed to delay the onset of these cytopenias, extending the duration of the disease. The involvement of rectum may be a poor prognostic sign in this patient. González et al. $^{25}$ reported that through experimental infection of hamsters with $L$. donovani, the rectum and colon were intensely parasitized in the end-stage of the disease, with a higher number of amastigote forms of Leishmania in these tissues than small intestine.

Considering the disease severity, the patient was initially treated with L-AmB. In Brazilian public health facilities with limited resources, as our institution, the treatment of $V L$ is provided by the Brazilian Health Ministry and is carried out according to the Brazilian guidelines for management of VL. In these guidelines, non-HIV-infected patients should be treated with L-AmB at a dose of $4 \mathrm{mg} / \mathrm{kg}$ daily for 5 days. ${ }^{6}$ The patient is older than 40 years and had a longer disease duration accompanied by diarrhea and hemorrhage besides a serum albumin $<30 \mathrm{~g} / \mathrm{L}$. All these factors are associated with a poor prognosis in VL. ${ }^{24}$ Therefore, this patient was given the best existing drug against Leishmania sp., that is, L-AmB. ${ }^{26}$

Generally, parasitological control is not part of cure criteria for $\mathrm{VL}^{5,6}$ because the clinical improvement correlates with parasitological response to the treatment. Non-sterile cure of 
Leishmania infection is considered the rule, even for immunocompetent persons, so parasitological reassessment is reserved to individual cases in which patients remain symptomatic or exhibit return of symptoms and signs. Thereby, because of the patient's unfavorable clinical course 2 months after the first treatment, another biopsy was performed. The presence of a high Leishmania burden in specimens demonstrated the persistence of disease, indicating the VL was refractory to treatment. We did not consider a relapse because of the short period between hospitalizations.

Combination therapy is not new in the treatment of infectious diseases. It seems the most appropriate treatment for intracellular pathogens, as we have learned from tuberculosis treatment. There are few drug options for VL, and drug resistance is consequently a concern. ${ }^{1,5}$ As in Mycobacterium tuberculosis, Leishmania sp. invade, survive, and multiply in host macrophages with four fates: stasis, division, death, or scape. ${ }^{27}$ Leishmania infection can modify macrophage metabolism that has an impact on drug activity and is a phenomena also seen with $M$. tuberculosis. ${ }^{27,28}$ These factors are known to influence the design of multidrug therapy for tuberculosis $^{27}$ and, by extrapolation, could influence VL treatment.

Multidrug therapy is pertinent for VL treatment, especially in immunocompromised hosts with refractory disease. ${ }^{1,5}$ This was our patient's clinical setting. It was also a therapeutic challenge. Most experience of combined treatment comes from patients with HIV/Leishmania coinfection and combination therapy with L-AmB and miltefosine is the preferential regimen in this situation. ${ }^{1,5,29}$ However, the optimal therapeutic regimen, including the drugs, dosing, and duration of therapy, has not been defined yet. In addition, miltefosine is not available for treatment of human VL in Brazil. Even so, considering the principles of combination therapy, we believed that our patient would benefit from this approach for the reasons listed in the following paragraphs.

Drug combinations could prevent the selection of drugresistant parasites. In most VL cases in immunosuppressed patients, therapeutic failure represents an immunological failure rather a drug failure. ${ }^{30}$ On the other hand, in regions where dogs are treated for canine leishmaniasis using the same anti-Leishmania drugs for human VL, it raises the concern about emergence of resistance to amphotericin $B .{ }^{31}$ The authors had had a previous experience of drug failure with $\mathrm{L}-\mathrm{AmB}$ in a child presenting a refractory VL without apparent immunosuppressive condition who responded to this triple combination therapy. ${ }^{32}$ Considering the possibility of parasite's resistance to amphotericin $B$, we decided to treat this patient with L-AmB, MA, and pentamidine, as previously reported. $^{32}$

When we combined the drugs for VL treatment, we could reduce the overall dose of each drug or, even, shorten the overall duration of the therapy. These potential advantages could mean more adherence to treatment with less cost. We treated the patient with a total cumulative dose of $40 \mathrm{mg} / \mathrm{kg}$ $\mathrm{L}-\mathrm{AmB}$ plus MA at $10 \mathrm{mg} / \mathrm{kg} /$ day and pentamidine isethionate at $3 \mathrm{mg} / \mathrm{kg}$ two times per week for 4 weeks.

Liposomal amphotericin B is the most expensive treatment regimen for $\mathrm{VL}$ and can achieve a cumulative dose as high as $60 \mathrm{mg} / \mathrm{kg}$ in refractory VL cases treated with monotherapy. Since 2010, to increase the access of L-AmB to developing countries (including Brazil), as part of Drugs for Neglected Diseases initiative projects, the WHO established an agreement with the manufacturer of the L-AmB (Gilead Sciences, Inc., San Dimas, CA) for reduction of the drug price in countries where VL is endemic. ${ }^{1}$ In Brazil, for a $60-\mathrm{kg}$ adult patient, the estimated direct costs of treatment of VL with $\mathrm{L}-\mathrm{AmB}$ at a cumulative dose of $21 \mathrm{mg} / \mathrm{kg}$, including costs of drugs, remuneration of health professionals, consumables, personal protective equipment, and complementary tests, were USD 659.79 and USD 11,559.15 using the WHOnegotiated price and the price adopted by The Drug Regulation Board from National Health Surveillance Agency/Ministry of Health from Brazil, respectively. ${ }^{33}$

As part of combination therapy, we decided to use a lower dose of MA (10 mg/kg per day) than the standard one $(20 \mathrm{mg} /$ $\mathrm{kg}$ per day) recommended for monotherapy by guidelines and the package insert, based on previous successful reports of rescue therapy with antimony low dose in immunocompromised patients with VL caused by L. infantum. In the study by Morizot et al., ${ }^{34}$ three immunocompromised patients (two HIV-infected patients with severe immunosuppression and a kidney transplant recipient with graft rejection), with VL unresponsive to $L-A m B$, either for therapeutic failure or for relapse, were given a 28-day course of antimony low dose (10 $\mathrm{mg} \mathrm{Sb}^{5+} / \mathrm{kg}$ per day for the HIV-infected patients and $170 \mathrm{mg} \mathrm{Sb}^{5+}$ per day, adjusted for renal clearance, for the kidney transplant recipient), resulting in rapid and sustained clinical and parasitological cure. Cota et al. ${ }^{35}$ reported that the treatment with antimony low dose was associated with similar clinical cure rate compared with antimony high dose in HIVinfected patients (58.4\% versus $58.7 \%$ ). Besides that, in Brazil, monotherapy with MA is extended to 8 weeks in refractory VL. ${ }^{36}$ This implies a longer period in hospital that consequently increases the cost of treatment.

The same rational applies to pentamidine isethionate. In Brazil, pentamidine is considered an alternative agent for treatment of $\mathrm{VL}$, and the recommended dose for Leishmania infection is $2-4 \mathrm{mg} / \mathrm{kg}$ every other day for $10-15$ applications, not to exceed a total dose of $2 \mathrm{~g} .{ }^{36}$ In refractory cases, pentamidine monotherapy can be extended up to 30 applications. ${ }^{5}$ After parenteral administration, the drug rapidly distributes to tissues, especially those belonging to reticuloendothelial system. ${ }^{37}$ Despite the low serum levels, the fraction bound to the proteins in serum is 55-69\%, allowing a slow release of the drug for long periods, with a terminal half-time of 12 days. ${ }^{37}$ In addition, the susceptible pathogens concentrate the drug in intracellular milieu using energy-dependent active transport. ${ }^{37}$ Taking these factors into account and the fact that by combining drugs from different classes, we could reduce the total dose of each drug, we decided to use a pentamidine lower dose.

One limitation of combined therapy is the possibility of drugrelated toxicity. The anti-Leishmania drugs are not free from potentially serious adverse events. ${ }^{1,5,6,36}$ Nevertheless, reducing the overall dose of each medicine could minimize their individual toxic effects. In HIV-infected patients, the treatment of VL with antimony low dose was associated with less frequent serious adverse events, but with a similar efficacy rate, compared with antimony high dose. ${ }^{35}$ In addition, the cardiotoxicity risk of pentavalent antimony, as well as the diabetes risk of pentamidine, seems to be cumulative and dose dependent. ${ }^{1,5,6,28,35,36}$

However, we cannot ignore the potential additive effect of toxicity from combination therapy. For example, L-AmB, MA, 
and pentamidine can all cause hematological, renal, and cardiac abnormalities. ${ }^{1,5,28}$ Pentamidine and MA can cause pancreatitis. ${ }^{5,28,36}$ The potential toxicity of combination therapy warrants that treatment should be performed in a facility where intensive care unit is available in case of serious adverse events. Therefore, toxicity must be monitored by periodic laboratory tests during treatment. Twice a week, our patient underwent a battery of laboratory tests for assessing the liver, kidney, and pancreatic functions; glucose level; blood cell counts; and electrocardiogram for heart rhythm disorders, according to the guidelines. ${ }^{5,6}$ These tests revealed no serious toxic effects in our patient.

This anti-Leishmania drug triple combination therapy is an empiric approach for VL treatment. Previously reported in children, ${ }^{32}$ this is the first time that such a multidrug therapy has been used in an adult patient with VL. The patient responded excellently with no serious side effects and all symptoms completely disappeared. Twelve months after the end of the treatment, he was still asymptomatic and there was a significant improvement in his condition. No relapse of disease was detected. We strongly believe that triple therapy was successful because each anti-Leishmania drug acts differently and that potentially there could be a synergistic activity.

Despite our promising result, the anti-Leishmania drug triple combination therapy should be restricted to VL cases that are difficult to treat in view of the possible dangers related to toxicity.

\section{CONCLUSION}

We report a case of disseminated VL in a splenectomized adult patient who was refractory to L-AmB therapy but who later responded successfully to a combination therapy of $L-A m B$, $M A$, and pentamidine isethionate. This led us to conclude that triple combination therapy with anti-Leishmania drugs is an option for the treatment of VL in immunocompromised individuals that are unresponsive to monotherapy. It should be reserved for refractory cases, especially when L-AmB treatment has failed. This regimen will potentially avoid resistance to L-AmB, which today is the most efficient drug for VL treatment.

Received December 21, 2018. Accepted for publication July 14, 2019.

Published online December 23, 2019.

Acknowledgments: We would like to thank the Hospital Giselda Trigueiro for technical assistance.

Authors' addresses: Hareton Teixeira Vechi, Mirella Alves Cunha, and Kleber Giovanni Luz, Department of Infectious Diseases, Hospital Giselda Trigueiro, Universidade Federal do Rio Grande do Norte, Rio Grande do Norte, Brazil, E-mails: haretonvechi@gmail.com, mirellaac@gmail.com, and klebergluz@gmail.com. Ana Solange Vasconcelos de Sousa, Hospital Giselda Trigueiro, Secretaria Estadual de Saúde Pública do Rio Grande do Norte, Rio Grande do Norte, Brazil, E-mail: anasolv@gmail.com. Jeffrey Jon Shaw, Department of Parasitology, Instituto de Ciências Biomédicas, São Paulo University, São Paulo, Brazil, E-mail: jayusp@hotmail.com.

\section{REFERENCES}

1. World Health Organization, 2010. Control of the Leishmaniases. Report of a Meeting of the WHO Expert Committee on Control of Leishmaniases. WHO Technical Report Series No. 949. Geneva, Switzerland, March 22-26, 2010.

2. Alvar J, Vélez ID, Bern C, Herrero M, Desjeux P, Cano J, Jannin J, den Boer M; WHO Leishmaniasis Control Team, 2012.
Leishmaniasis worldwide and global estimates of its incidence. PLoS One 7: e35671.

3. Lindoso JA, Cota GF, Cruz AMda, Goto H, Maia-Elkhoury ANS, Romero GAS, Sousa-Gomes MLde, Santos-Oliveira JR, Rabello A, 2014. Visceral leishmaniasis and HIV coinfection in Latin America. PLoS Negl Trop Dis 8: e3136.

4. Saporito L, Giammanco GM, De Grazia S, Colomba C, 2013. Visceral leishmaniasis: host-parasite interactions and clinical presentation in the immunocompetent and in the immunocompromised host. Int J Infect Dis 17: e572-e576.

5. Aronson N, Herwaldt BL, Libman M, Pearson R, Lopez-velez R, Weina P, Carvalho EM, Ephros M, 2018. Diagnosis and treatment of leishmaniasis: clinical practice guidelines by the Infectious Diseases Society of America (IDSA) and the American Society of Tropical Medicine and Hygiene (ASTMH). Clin Infect Dis 63: e202-e264.

6. Ministério da Saúde do Brasil, 2011. Leishmaniose Visceral: Recomendações Clínicas para Redução da Letalidade, 1st edition. Brasília, Brazil: Editora do Ministério da Saúde, 17-30.

7. Olea $P, 2013$. Leishmaniosis visceral en un paciente con infección por VIH. Rev Chil Infectol 30: 216-220.

8. Agarwal P, Kumar V, Kaushal M, Kumari M, Chaudhary A, 2017. Indian visceral leishmaniasis with extensive lymphadenopathyan unusual presentation: a case report with literature review. Cytojournal 14: 9.

9. Eibl M, 1985. Immunological consequences of splenectomy. Prog Pediatr Surg 18: 139-145.

10. Siddig M, Ghalib H, Shillington DC, Petersen EA, Khidir S, 1990. Visceral leishmaniasis in Sudan. Clinical features. Trop Geogr Med 42: 107-112.

11. Pomares-Estran C, Cenderello G, Ittel A, Karsenti JM, CardotLeccia N, Vassalo M, Hasseine L, Delaunay P, Rosenthal E, Marty P, 2009. Isolated Iymphadenopathy in Leishmania infantum infection: three case reports. Ann Trop Med Parasitol 103: 555-559.

12. Aleixo JA, Nascimento ET, Monteiro GR, Fernandes MZ, Ramos AMO, Wilson ME, Pearson RD, Jeronimo SMB, 2006. Atypical American visceral leishmaniasis caused by disseminated Leishmania amazonensis infection presenting with hepatitis and adenopathy. Trans R Soc Trop Med Hyg 100: 79-82.

13. Adamama-moraitou KK, Rallis TS, Koytinas AF, Tontis D, Plevraki $\mathrm{K}$, Kritsepi M, 2007. Asymptomatic colitis in naturally infected dogs with Leishmania infantum: a prospective study. Am J Trop Med Hyg 76: 53-57.

14. Idoate MA, Vazquez JJ, Civeira P, 1993. Rectal biopsy as a diagnostic procedure of chronic visceral leishmaniasis. Histopathology 22: 589-590.

15. Napier LE, 1949. Splenectomy in the treatment of kala-azar. $J$ Trop Med Hyg 52: 243-248.

16. Dutra RA, Dutra LF, Reis Mde O, Lambert RC, 2012. Splenectomy in a patient with treatment-resistant visceral leishmaniasis: a case report. Rev Soc Bras Med Trop 45: 130-131.

17. Kumar R, Daga MK, Kamble NL, Sothwal A, Singh T, Nayak HK, Raizada N, 2011. Rare association of visceral leishmaniasis with Hodgkin's disease: a case report. Infect Agent Cancer 6: 17.

18. Osakwe NM, Paulus A, Haggerty PF, Wood RA, Becker SJ, Weina PJ, Dolan MJ, Prakash V, 2013. Visceral leishmaniasis with associated immune dysregulation leading to lymphoma. Mil Med 178: e386-e389.

19. Cartwright GE, Chung H-L, Chang A, 1948. Studies on the pancytopenia of kala-azar. Blood 3: 249-275.

20. Varma N, Naseem S, 2010. Hematologic changes in visceral leishmaniasis/kala azar. Indian J Hematol Blood Transfus 26: 78-82.

21. Magill AJ, 2015. Leishmania species: visceral (kala-azar), cutaneous, and mucosal leishmaniasis. Bennett JE, Dolin R, Blaser MJ, eds. Mandell, Douglas, and Bennett's Principles and Practice of Infectious Diseases, 8th edition. Philadelphia, PA: Elsevier Saunders, 3097.

22. McBride JA, Dacie JV, Shapley R, 1968. The effect of splenectomy on the leucocyte count. Br J Haematol 14: 225-231.

23. Chapman LAC, Dyson L, Courtenay O, Chowdhury R, Bern C, Medley GF, Hollingsworth TD, 2015. Quantification of the 
natural history of visceral leishmaniasis and consequences for control. Parasit Vectors 8: 521.

24. Belo VS, Struchiner CJ, Barbosa DS, Nascimento BWL, Horta MAP, da Silva ES, Werneck GL, 2014. Risk factors for adverse prognosis and death in American visceral leishmaniasis: a meta-analysis. PLoS Negl Trop Dis 8: e2982.

25. Gonzáilez JL, Insa F, Novoa C, Pizarro M, 1986. Intestinal amyloidosis in hamsters with visceral leishmaniasis. Br J Exp Path 67:353-360.

26. Chattopadhyay A, Jafurulla $M, 2011$. A novel mechanism for an old drug: amphotericin B in the treatment of visceral leishmaniasis. Biochem Biophys Res Commun 416: 7-12.

27. Croft SL, 2018. Leishmania and other intracellular pathogens: selectivity, drug distribution and PK-PD. Parasitology 145: 237-247.

28. Croft S, Yardley V, 2002. Chemotherapy of leishmaniasis. Curr Pharm Des 8: 319-342.

29. Van Griensven J, Carrillo E, López-Vélez R, Lynen L, Moreno J, 2014. Leishmaniasis in immunosuppressed individuals. Clin Microbiol Infect 20: 286-299.

30. Lachaud L, Bourgeois N, Plourde M, Leprohon P, Bastien P, Ouellette M, 2009. Parasite susceptibility to amphotericin B in failures of treatment for visceral leishmaniasis in patients coinfected with HIV type 1 and Leishmania infantum. Clin Infect Dis 48: e16-e22.

31. Maia C, Nunes M, Marques M, Henriques S, Rolão N, Campino L, 2013. In vitro drug susceptibility of Leishmania infantum isolated from humans and dogs. Exp Parasitol 135: 36-41.
32. Gomes MAF, Medeiros LLC, Lobo FPD, Wanderley NRS, Matos APR, Jácome TDN, Monteiro MGL, Luz KG, 2018. Combination therapy with liposomal amphotericin b (Ambisome), n-methylglucamine antimoniate (glucantime), and pentamidine isethionate in a refractory visceral leishmaniasis case. Rev Soc Bras Med Trop 51: 393-396.

33. Assis TSM, Rosa DCP, Teixeira EM, Cota G, Azeredo-da-Silva ALF, Werneck G, Rabello A, 2017. The direct costs of treating human visceral leishmaniasis in Brazil. Rev da Soc Bras Med Trop 50: 478-482.

34. Morizot $\mathrm{G}$ et al., 2016. Antimony to cure visceral leishmaniasis unresponsive to liposomal amphotericin B. PLoS Negl Trop Dis 10: e0004304.

35. Cota GF, de Sousa MR, Fereguetti TO, Rabello A, 2013. Efficacy of anti-leishmania therapy in visceral leishmaniasis among HIV infected patients: a systematic review with indirect comparison. PLoS Negl Trop Dis 7: e2195.

36. Ministério da Saúde do Brasil, 2006. Tratamento. Manual de Vigilância e Controle da Leishmaniose Visceral, 1st edition. Brasília, Brazil: Editora do Ministério da Saúde, 31-40.

37. Woods ML, 2018. Pentamidine. Grayson ML, Cosgrove SE, Crowe SM, Hope W, Mccarthy JS, Mills J, Mouton JW, Paterson DL, eds. Kucers' the Use of Antibiotics : A Clinical Review of Antibacterial, Antifungal, Antiparasitic and Antiviral Drugs, 7th edition. Boca Raton, FL: CRC Press, 33243331. 